\title{
Trans-Pacific ENSO teleconnections pose a correlated risk to agriculture
}

\author{
Weston Anderson ${ }^{\mathrm{a}, *}$, Richard Seager ${ }^{\mathrm{a}}$, Walter Baethgen ${ }^{\mathrm{b}}$, Mark Cane $^{\mathrm{a}}$ \\ a Lamont-Doherty Earth Observatory, Columbia University, Palisades, NY, United States \\ ${ }^{\mathbf{b}}$ International Research Institute for Climate and Society, Palisades, NY, United States
}

\section{A R T I C L E I N F O}

\section{Keywords:}

El Niño Southern Oscillation (ENSO)

La Niña

Crop yield

ENSO teleconnection

Food security

Drought

\begin{abstract}
A B S T R A C T
The El Niño Southern Oscillation (ENSO) is a major source of interannual climate variability. ENSO life cycles and the associated teleconnections evolve over multiple years at a global scale. This analysis is the first attempt to characterize the structure of the risk posed by trans-Pacific ENSO teleconnections to crop production in the greater Pacific Basin region.

In this analysis we identify the large-scale atmospheric dynamics of ENSO teleconnections that affect heat and moisture stress during the growing seasons of maize, wheat and soy. We propose a coherent framework for understanding how trans-Pacific ENSO teleconnections pose a correlated risk to crop yields in major agricultural belts of the Americas, Australia and China over the course of an ENSO life cycle by using observations and a multi-model ensemble of climate anomalies during crop flowering seasons.

Trans-Pacific ENSO teleconnections are often (but not always) offsetting between major producing regions in the Americas and those in northern China or Australia. El Niños tend to create good maize and soybean growing conditions in the US and southeast South America, but poor growing conditions in northern China, southern Mexico and the Cerrado in Brazil. The opposite is true during La Niña. Wheat growing conditions in southeast South America generally have the opposite sign of those in Australia. Furthermore, multi-year La Niñas can force multi-year growing season anomalies in Argentina and Australia.

Most ENSO teleconnections relevant for crop flowering seasons are the result of a single trans-Pacific circulation anomaly that develops in boreal summer and persists through the following spring. During the late summer and early fall of a developing ENSO event, the tropical Pacific forces an atmospheric anomaly in the northern midlatitudes that spans the Pacific from northern China to North America and in the southern midlatitudes from Australia to southeast South America. This anomaly directly links the soybean and maize growing seasons of the US, Mexico and China and the wheat growing seasons of Argentina, southern Brazil and Australia. The ENSO event peaks in boreal winter, when the atmospheric circulation anomalies intensify and affect maize and soybeans in southeast South America. As the event decays, the ENSO-induced circulation anomalies persist through the wheat flowering seasons in China and the US.
\end{abstract}

\section{Introduction}

In a global economy, food insecurity can be caused not only by local crop failures, but also by crop failures in distant food-exporting regions (Puma et al., 2015; Marchand et al., 2016). Crop failures in major producing regions can increase food prices globally with greatest impact on import dependent trade partners (d'Amour et al., 2016). Understanding the food security of any nation, region, or the world, therefore, requires that we understand production variability globally and how this impacts food availability via the global food trade system. Of particular interest is the co-variability of major food producing regions - do they tend to vary in-phase or out-of-phase generating compounding or offsetting global-scale production variability?

Climate variability, although only one of many factors that determines food security, is one process that can affect the crop yields of geographically distant regions simultaneously or in sequence. The El Niño Southern Oscillation (ENSO), as a major source of temperature and precipitation variability, is among the most important modes of climate variability for global food security (Trenberth et al., 1998; Mason and Goddard, 2001). Spatially, both El Niño and La Niña have distinct patterns of teleconnections to climate at a global scale (Bjerknes, 1969; Trenberth et al., 1998; Alexander et al., 2002). From an interannual perspective, ENSO exhibits a characteristic multi-year life cycle of sea surface temperature (SST) and zonal wind anomalies

\footnotetext{
* Corresponding author at: Lamont-Doherty Earth Observatory, 61 Route 9W, Palisades, NY 10964, United States.

E-mail address: weston@1deo.columbia.edu (W. Anderson).
} 
(Rasmusson and Carpenter, 1982). Furthermore, the transition from an El Niño state to a La Niña state tends to be phase locked to the seasonal cycle (Wang and Picaut, 2004), and therefore intersects crop flowering seasons in a predictable manner. By creating unfavorable growing conditions in many regions simultaneously or in sequence (Anderson et al., 2016), ENSO can pose a correlated risk to crop production in our globalized agricultural economy (Anderson et al., 2017).

Recent studies have detailed the impacts of ENSO on crop yields globally (Iizumi et al., 2014), but we lack a unified framework for understanding the mechanisms behind how these yield anomalies relate to one another. This is, in part, because the climate analyses of global ENSO teleconnections often focus on the season when teleconnections are strongest rather than the seasons when crops are most vulnerable to climate anomalies. And while there are studies that analyze the dynamic processes by which ENSO affects crop yields, these tend to be regional analyses that focus on one specific season. Fragmenting the literature in this way makes it difficult to understand how ENSO-induced crop yield anomalies relate to one-another.

For example, when considering major soybean producers we might be interested in how ENSO-induced yield anomalies in the United States relate to those in China and Southeast South America. Are they all part of a single circulation pattern that spans the basin and persists throughout the year or is each region affected by independent teleconnections that develop locally at different times of the year? Do El Niño or La Niña events (hereafter generalized as ENSO events) have the same impacts on production in all regions or are losses in one region and at one time compensated for by gains elsewhere and at other times? Answering these questions is critical for understanding how closely linked the yield anomalies are, but doing so requires considering both spatial variations in the climate teleconnections and the timing of each circulation anomaly in relation to major crop growing seasons.

In this analysis we will address two main questions: (1) How are ENSO climate teleconnections during the growing seasons in the Americas, China and Australia related to one another? and (2) Within a single growing year, are ENSO-forced heat and moisture stress anomalies generally compounding or offsetting across major producing regions?

In the following sections we will first identify the trans-Pacific atmospheric teleconnections relevant during the growing seasons of maize, wheat and soy. Next, we translate the climate variables into measures that are relevant for agriculture (soil moisture and killing degree days). We then use a multi-model ensemble to identify which teleconnections from the observational analysis are most robust. Through these analyses we construct a coherent framework, which we summarize in the final section, for understanding how trans-Pacific ENSO teleconnections affect crops over the course of an ENSO life cycle.

\section{Methods and data}

To analyze how life cycles of ENSO affect crop growing conditions in the greater Pacific basin region, we (1) identify relevant ENSO years, (2) define the climate sensitive months of the local growing season at each location during those years, and (3) define metrics of heat and moisture stress during those months to use in a composite analysis. To analyze the global atmospheric dynamics that give rise to local growing season teleconnections, we define a discreet number of seasons that include the climate-sensitive portions of local growing seasons. We then create composites of atmospheric variables during these seasons for each year in the ENSO life cycle. Finally, we estimate how robust observed teleconnections during local growing seasons are by using an ensemble of SST-forced atmospheric models. In the following sections we describe the methods and data used in each of these analyses.

\subsection{Defining ENSO life cycles}

The first step in our analysis is to construct ENSO life cycles. To do so, we identify years in which the October-November-December SST anomaly in the Niño 3.4 region as measured by the Oceanic Niño Index ${ }^{1}$ exceeded 0.5 standard deviations, which corresponds to an absolute departure of just under $0.5^{\circ} \mathrm{C}$. These ENSO 'event years' are listed in grey above panels 1 and 2 of Fig. 1 . Each life cycle consists of three years: an 'event year' as well as one year preceding and one year following the event. Years were not allowed to be double counted as an 'event year' in one life cycle and as a following or preceding year in another life cycle. Because SST anomalies in the Niño 3.4 region tend to develop and decay in boreal spring (Rasmusson and Carpenter, 1982; or see Fig. 1), we use a May-April 'ENSO year'.

\subsection{Identifying climate sensitive portions of the growing season}

How crop yields respond to an abiotic stress depends on the stage of development at which the stress is applied. Many crops are relatively insensitive to stresses applied during the vegetative stages of development but respond strongly to stress applied around the time of flowering, which determines the number of grains that develop per planted area (Siebers et al., 2017; Barnabás et al., 2008). We use the global crop calendar of Sacks et al. (2010) to estimate crop harvest dates by location and consider the three months prior to harvest as the season around flowering. We use the primary harvest dates from the Sacks et al. (2010) data where multiple harvest dates are available for maize. For wheat, we use winter wheat harvest dates in all countries except Australia and Canada, where we use spring wheat harvests. While both the US and China grow a spring wheat crop, we choose to focus our analysis on the larger winter wheat crop. These data constraints prevent our analysis from addressing nuances within individual countries, such as teleconnections to regions growing alternate season wheat. Our results instead focus only on the primary growing season of each crop in each country. We furthermore use the static harvest dates of Sacks et al. (2010), although in practice planting and harvest dates will be variable and may depend on the growing conditions for that year. The dataset is largely interpolation in some regions, such as northeast Brazil and parts of China (see Sacks et al., 2010 for details), which may bias our results in these areas. Although the crop calendars in Sacks et al. (2010) are subnational, we include a simplified country-level approximation of the crop calendars in the bottom three panels of Fig. 1 for comparison to the ENSO life cycles in the top two panels.

To mask out minor and non-producing regions, we only plot teleconnections for locations in which the harvested area of a given crop corresponded to at least $0.1 \%$ of the total area for that pixel according to the Monfreda et al. (2008) dataset of global harvested areas. While the Monfreda et al. (2008) dataset represents harvested areas around the year 2000, actual harvested areas may have changed over time in some regions (most notably in Brazil).

\subsection{Calculating crop-relevant variables}

Even when climate teleconnections exist during crop flowering seasons, they do not always translate to yield anomalies. Crop yields respond not to variations in precipitation directly but rather to soil moisture anomalies. We use $0-1 \mathrm{~m}$ soil moisture estimates from the Noah Land surface model version 3.3 in the Global Land Data Assimilation System version 2 (Rodell and Kato Beaudoing, 2015), which is available from 1948 to 2010 , to calculate the average soil moisture anomaly during the flowering season. We average the flowering season soil moisture over the years identified in Fig. 1 to estimate ENSO teleconnections for each year in the life cycle.

In terms of temperature, crop yields benefit from increases in growing season temperature up to a biophysical threshold, at which

\footnotetext{
${ }^{1}$ Data available from https://catalog.data.gov/dataset/climate-predictioncenter-cpcoceanic-nino-index.
} 

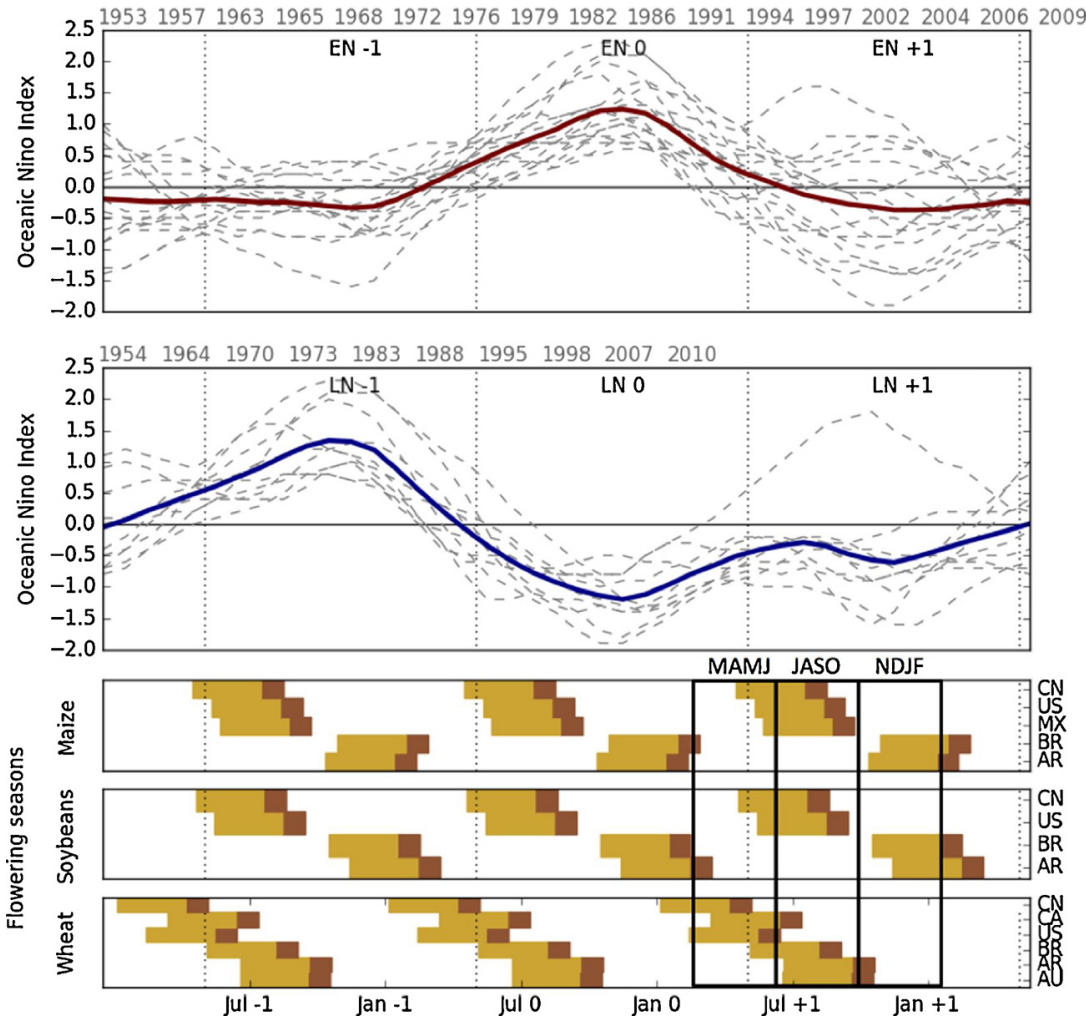

Fig. 1. Three year El Niño (top panel) and La Niña (second panel) composites of the Oceanic NiñoIndex, which is calculated as the three month running mean of sea surface temperatures inthe Niño 3.4 region. Ensemble mean shown in bold. Ensemble event years (EN 0 or LN 0)in grey above each panel. Rows three, four and five are a simplified representation of harvestmonths (brown) and the three months around flowering (gold) based on Sacks et al. (2010).Black boxes indicate seasons used in the atmospheric analysis. point increases in temperature damage the reproductive organs of the plant and cause declines in yields (Schlenker and Roberts, 2009). To isolate the impact of harmful increases in maximum temperature around flowering, we follow the methods of Schlenker and Roberts (2009) and Tai et al. (2014; Supplementary Information) by using critical temperature thresholds $\left(T_{c}\right)$ for wheat, maize and soybean as $26^{\circ} \mathrm{C}$, $29^{\circ} \mathrm{C}$ and $30^{\circ} \mathrm{C}$, respectively. Temperature thresholds are chosen to identify detrimental, not necessarily lethal, temperatures. During the three months around flowering, the number of 'killing degree days' (KDD) were then calculated using the Berkeley Earth daily maximum $2 \mathrm{~m}$ temperature data of Rohde et al. (2013a, 2013b) as follows:

$K D D=\sum_{i=1}^{n} \max \left(0, T_{\max , i}-T_{c}\right)$

where $T_{\max , i}$ is the maximum temperature on the ith day of the flowering period (that lasts $n$ days). As with soil moisture, this calculation is performed for all years from 1948 to 2010 and composites are created by averaging across all ENSO years.

\subsection{Creating seasonal composites of atmospheric teleconnections}

To understand whether ENSO poses a correlated risk to agriculture in the Americas, China and Australia, it is necessary to analyze the evolution of large-scale atmospheric circulations over the course of ENSO life cycles. Using the same ENSO years identified in Fig. 1, we create seasonal composites of ENSO teleconnections by averaging across all months in a season and across all ENSO events. We use ERSSTv3b (Smith et al., 2008) for data on SST anomalies. For geopotential height, vertical ascent and wind anomalies at $700 \mathrm{hPa}$, we use the NCEP-NCAR Reanalysis I for the years 1948-2010 (Kalnay et al., 1996). We choose to show the $700 \mathrm{hPa}$ pressure level as it is relevant for large-scale moisture transport. Atmospheric wind anomalies, which were analyzed but not shown, may be inferred from geopotential height anomalies assuming geostrophy: low pressure anomalies are associated with cyclonic flow (counter-clockwise in the northern hemisphere, clockwise in the southern hemisphere) while high-pressure anomalies are associated with anti-cyclonic flow.

We analyze the large-scale atmospheric dynamics of ENSO teleconnections using three seasons: the early season (March, April, May, June; MAMJ), mid-season (July, August, September, October; JASO), and late season (November, December, January, February; NDJF). These seasons were chosen to overlap with crop flowering seasons, as depicted by rectangles in the bottom panels of Fig. 1. As we later demonstrate in section 3.2, the early season is broadly relevant for the winter wheat growing season in China, Canada and the United States. The mid-season is an imperfect compromise between northern hemisphere maize and soybean flowering seasons and southern hemisphere wheat flowering seasons. Teleconnections in the late season affect southern hemisphere maize and soybean flowering seasons.

\subsection{Evaluating teleconnections using AMIP models}

To evaluate which growing season teleconnections from the observational analysis are most robust, we use a multi-model ensemble from the CMIP5 Atmospheric Model Intercomparison Project (AMIP), in which atmospheric general circulation models are forced with observed SST and sea-ice boundary conditions (Taylor et al., 2012). From the CMIP5 archive we select only those models that have at least 5 ensemble members (CSIRO-Mk3-6-0, CCSM4, GFDL-CM3 and IPSL-CM5ALR have 10, 5, 5, and 5 ensemble members, respectively). Compared to the single realization available in the historical record, the AMIP ensemble provides us with 25 . Since the weather in each model simulation is uncorrelated with that in each other, averaging across the ensemble isolates the SST-forced component common to all. Comparison to the AMIP ensemble, therefore, allows us to evaluate whether the anomalies in the observed record are truly SST-forced or an artefact of random climate "noise" that has not averaged to zero in the composites due to the limited length of the historical record. We calculate the multi-model mean by first averaging over the ensembles of each model then averaging over all models. We use the same flowering seasons as before to calculate the mean of the $2 \mathrm{~m}$ daily maximum temperature and seasonal precipitation anomalies, but (due to limited data availability) are 
unable to calculate soil moisture or killing degree days for the AMIP models. Using a multi-model ensemble and ensemble averaging allows a more robust estimation of SST-forced variability than is possible in the observational record, but it is subject to model bias.

To further isolate the climate anomalies forced by the tropical Pacific, rather than the global SST-forcing used in the AMIP models, we use runs from a single atmospheric general circulation model (CCM3) forced with observed SST anomalies in the tropical Pacific and climatological SSTs elsewhere (see the appendix for further details; Seager et al., 2005). This analysis confirms the dominance of the tropical Pacific in forcing the observed climate anomalies.

\section{Results}

\subsection{The timing of ENSO Life cycles and crop growing seasons}

Following the growth of SST anomalies during an El Niño year (hereafter referred to as ENO) in boreal summer, SSTs tend to peak during late boreal fall, at which point they either decay back to neutral (an EN + 1 year) or the Bjerknes feedback is established in the opposite sense and the system enters a La Niña state (an LNO year; Rasmusson and Carpenter, 1982; see Fig. 1). La Niñas tend to persist for more than one year as the SST anomalies in the system slowly return to neutral over the course of two years (Okumura and Deser, 2010; DiNezio and Deser, 2014).

Southern hemisphere maize and soybean crops flower during the months of maximum ENSO SST anomalies, while northern hemisphere crops tend to flower during the development or decay stages (Fig. 1). In the southern hemisphere, wheat flowering occurs just prior to the peak of SST anomalies. In the northern hemisphere, although the flowering season occurs during near-neutral SST anomalies, there is evidence that these seasons may be affected by lagged teleconnections from the previous winter, when SST forcing is at its strongest (Mauget and Upchurch, 1999; Anderson et al., 2016; Wang et al., 2000, 2001a, 2001b; Weng et al., 2007)

\subsection{The atmospheric dynamics of ENSO life cycles}

During an ENSO life cycle, tropical Pacific SST anomalies can affect the atmosphere directly or they can force SST anomalies in the Indian and West-Pacific Basins, which then affect the atmospheric circulation a season later. In the following sections we will walk through, season-byseason, the development of SST anomalies and their impact on the atmospheric circulation during an ENSO life cycle. For reasons that will become clear, we begin our analysis with the JASO season.

\subsubsection{Mid-season (JASO) atmospheric teleconnections}

Teleconnections at the beginning (July and August) of the midseason are relevant for northern hemisphere soybean and maize flowering seasons (Fig. 1). During a developing El Niño (EN0 / LN-1), a cyclonic anomaly stretches across the north Pacific from Northeast China to the United States (see Figs. 2 and 3). On the western flank of the cyclonic anomaly equatorward flow over east China is associated with anomalous descent, which we may expect to inhibit convection and lead to dry conditions. This is consistent with a balance between vortex compression (anomalous descent) and advection of planetary vorticity (i.e. Sverdrup balance). The eastern flank of the cyclonic anomaly is associated with poleward wind anomalies and anomalous ascent (vortex stretching). Given a moisture source we would expect this ascent to lead to positive precipitation anomalies, although it is not clear that the anomalous ascent extends into the major maize producing region of the US. During La Niña (LNO), a trans-Pacific wave-train places ridges over the United States, the North Pacific and Eastern China. The ridge over the US is intensified at higher levels (not shown) and coincides with major maize and soy growing regions. The high pressure center off the east coast of China leads to poleward flow over central China and therefore anomalous ascent. A second ridge over farnorth China leads to equatorward motion and descent. We will show later that, similar to the North Pacific cyclonic anomaly in ENO, these anticyclonic anomalies are directly forced by tropical Pacific SST anomalies.

The second half of the mid-season (September and October) is relevant for wheat in the southern hemisphere, notably southeast South America and Australia. As in the Northern Hemisphere, a single cyclonic anomaly stretches across the South Pacific during a developing El Niño. The eastern and western edges of the circulation roughly coincide with the continents (ENO in Fig. 2; LN-1 in Fig. 3). The western flank (over Australia) coincides with equatorward motion, descent and anomalously dry conditions. This is consistent with Chiew et al. (1998). The eastern edge of the circulation, along with an anticyclonic circulation that develops at higher levels over southeast South America, induce poleward flow, anomalous ascent and therefore positive precipitation anomalies over east Argentina (Grimm et al., 2000; CazesBoezio et al., 2003; Anderson et al., 2016). During La Niña (LN0) these circulations essentially reverse, although the trough over the south Pacific shifts west such that the cyclonic circulation over southeast South America (and associated precipitation anomalies) also shift southwest relative to ENO.

\subsubsection{Late season (NDJF) atmospheric teleconnections}

The late season, which coincides with maximum SST anomalies, is relevant for southern hemisphere maize and soybean flowering seasons in southeast South America. During El Niño (ENO) events, a GillMatsuno-type response to tropical heating anomalies is visible in the tropics (Gill, 1980; Matsuno, 1996), which we discuss further in the next section. The mid-latitude wave-train radiating out from the tropics establishes a ridge over subtropical South America, which induces poleward motion and anomalous ascent over subtropical South America, but contributes to equatorward motion and anomalous descent over north-east Brazil (Grimm et al., 2000; Grimm, 2003; CazesBoezio et al., 2003; Zhou and Lau, 2001; Grimm et al., 1998). The ridge over southeast South America during El Niño and trough during La Niña are more clearly visible at $200 \mathrm{hPa}$ (see Appendix Fig. A1). These atmospheric motions set up a dipole in precipitation such that southeast South America is wet while northeast Brazil is dry. During La Niña events (LN 0 in Fig. 3) the circulation is generally opposite that of El Niño (EN0, LN-1) although, as in the mid-season, the circulation anomaly over southeast South America is shifted southwest during LNO. During second-year La Niñas $(\mathrm{LN}+1)$ the circulation over southeast South America is similar to that in LNO, but weaker.

SST anomalies during the late season affect not only the atmosphere but also remote ocean basins. During an El Niño event, subsidence over the Indian Ocean reduces cloud cover and increases absorbed solar radiation, which increases SSTs in the region. This basin-wide warming of the Indian Ocean persists into the following seasons and continues to influence the atmosphere months after SSTs have peaked in the eastern Pacific (Klein et al., 1999; Xie et al., 2009; Wu et al., 2010).

\subsubsection{Early season (MAMJ) atmospheric teleconnections}

The early season coincides with either (1) the nascent stages of developing warm SST anomalies or (2) a transition between warm and cold SST anomalies (see Fig. 1). In the absence of a strong tropical Pacific SST forcing, major aspects of the atmospheric circulation represent the persistence of a response to ENSO SST anomalies from the previous season. For example, the ridge off the east coast of China in the La Niña following an El Niño (see LNO in Fig. 3) first develops in the late-season of the previous year (NDJF LN-1 in Fig. 3) as a remote response to central Pacific SST anomalies but is sustained by a combination of local SST anomalies in the west Pacific (Wang et al., 2001a, 2000) and Indian Ocean SST anomalies (Xie et al., 2009; Wu et al., 2010). The anticyclonic circulation around this ridge is associated with poleward, rising air over east China that increases precipitation. 
EN -1
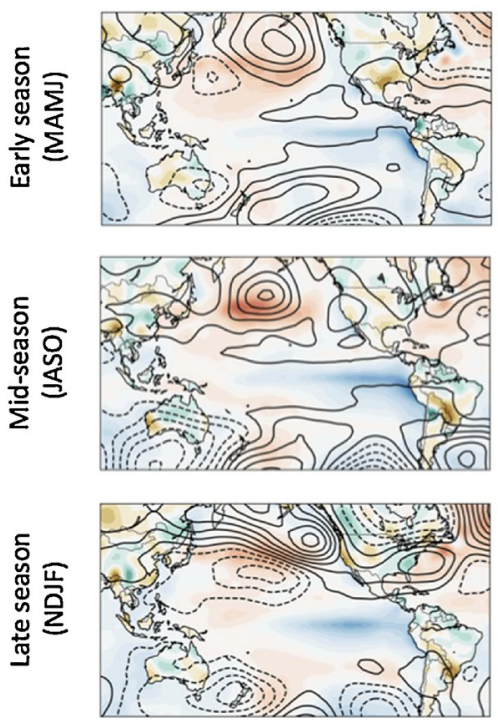

EN 0
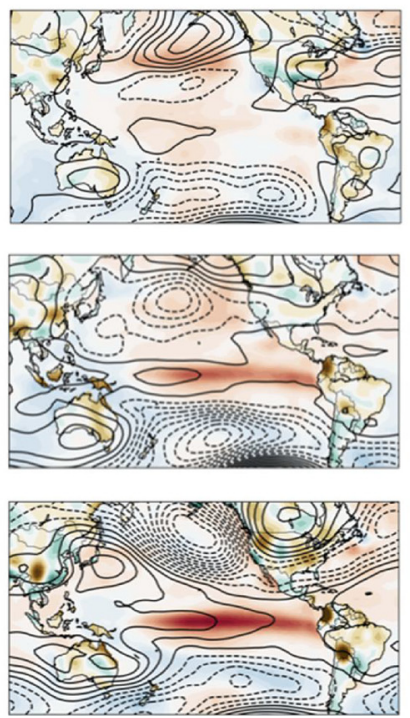

$\mathrm{EN}+1$
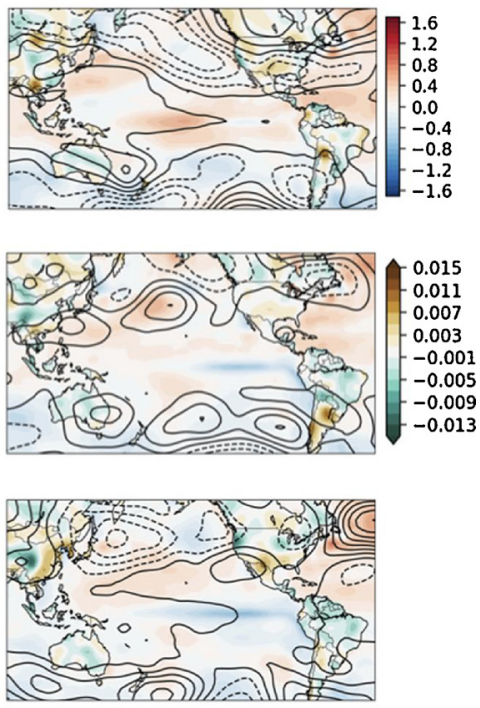

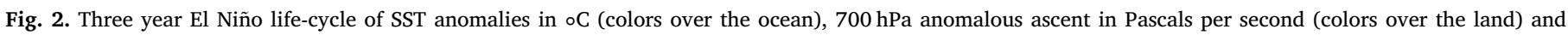
geopotential height at $700 \mathrm{hPa}$ (contours every $2.5 \mathrm{hPa}$ ) in the top three panels.

Previous studies have found that following an ENSO event, the Indian Ocean can affect the atmospheric circulation over both Australia and China (Taschetto et al., 2011; Annamalai et al., 2005; Yang et al., 2010, 2007)

The extratropical atmospheric anomalies in the northeastern Pacific appear to have persisted from the tropical SST-forced anomalies of the previous season (NDJF; see Figs. 2 and 3). In the year following an El Niño (EN + 1, LNO) a cyclonic anomaly, which was established strongly in NDJF of the previous year, extends over the North Pacific and the United States. In the year following a La Niña ( $\mathrm{LN}+1$, Fig. 3), the pattern is reversed.

\subsubsection{The dynamics of ENSO teleconnections in atmospheric models}

To confirm that the spatial extent and seasonal evolution of observed atmospheric anomalies are, in fact, the result of tropical Pacific SST anomalies, we use a series of model simulations that force an atmospheric general circulation model with SST anomalies from the tropical Pacific during ENO and LNO (Appendix Fig. 1) events. The ENSO-forced atmospheric anomalies take the form of a tropical Matsuno-Gill-type response that develops in the late summer and persists through to the following spring. The tropical response drives global teleconnections that affect the climate on continents in all four corners of the Pacific basin. During the late summer and early fall of a developing El Niño or La Niña, the tropical Pacific forces an atmospheric anomaly in the northern midlatitudes that spans the Pacific from northern China to North America and in the southern midlatitudes from Australia to southeast South America. This teleconnection directly links the soybean and maize growing seasons of the US, Mexico and China. It also connects the wheat growing seasons of Argentina, southern Brazil and Australia. The ENSO event peaks in boreal winter, when the atmospheric circulation anomalies intensify and affect maize and soybeans in southeast South America. As the event decays, the ENSO-
LN -1
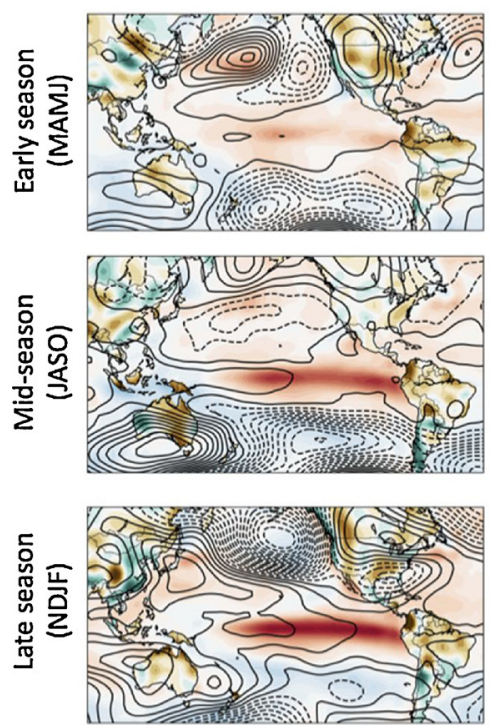

LN 0
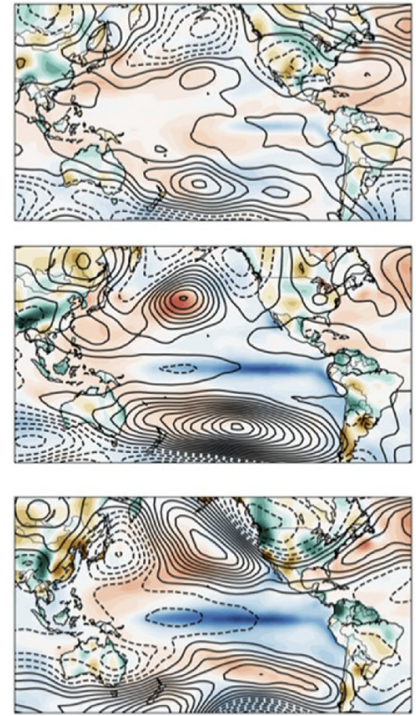

$\mathrm{LN}+1$
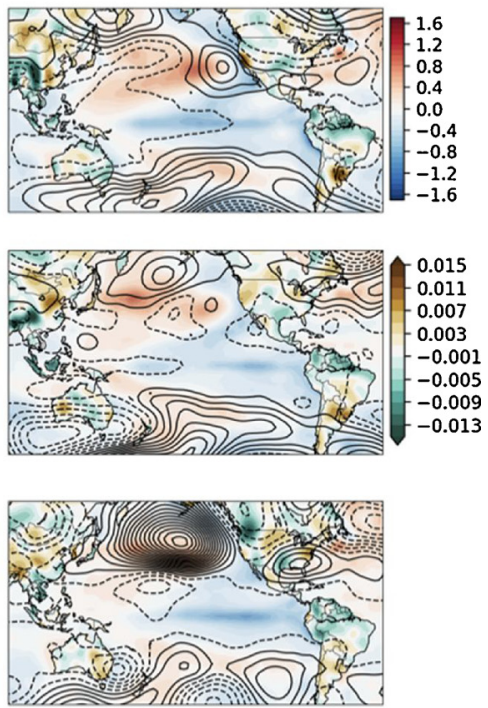

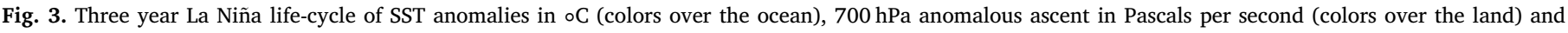
geopotential height at $700 \mathrm{hPa}$ (contours every $2.5 \mathrm{hPa}$ ) in the top three panels. 
EN -1

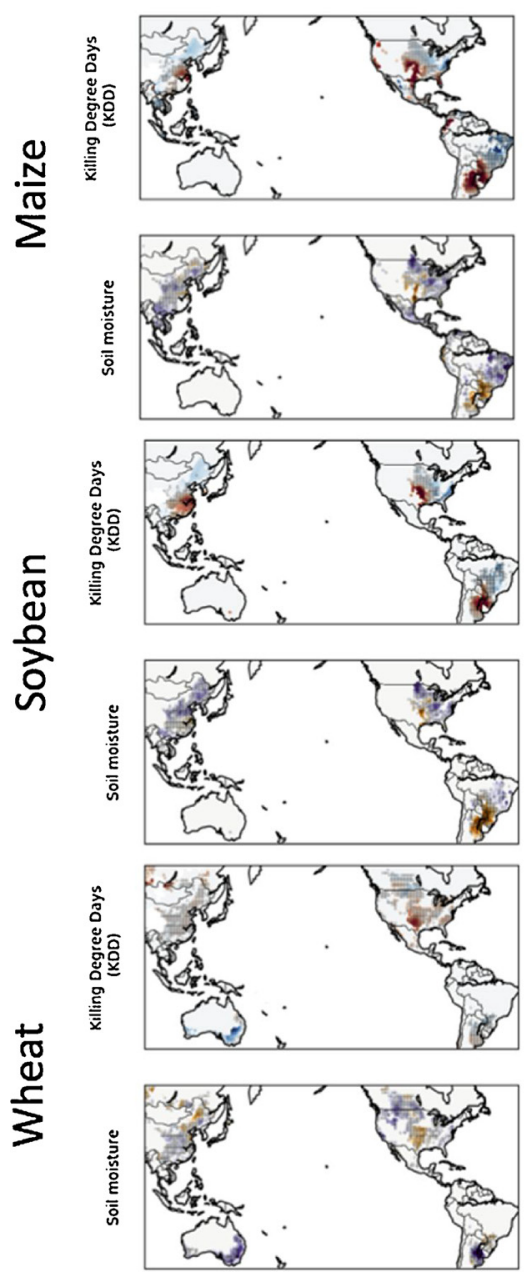

EN 0
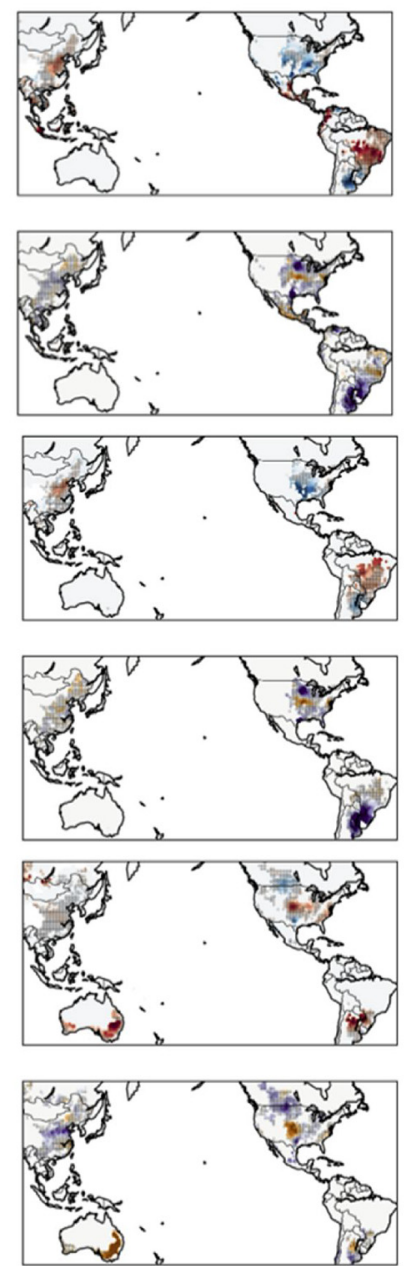

$\mathrm{EN}+1$
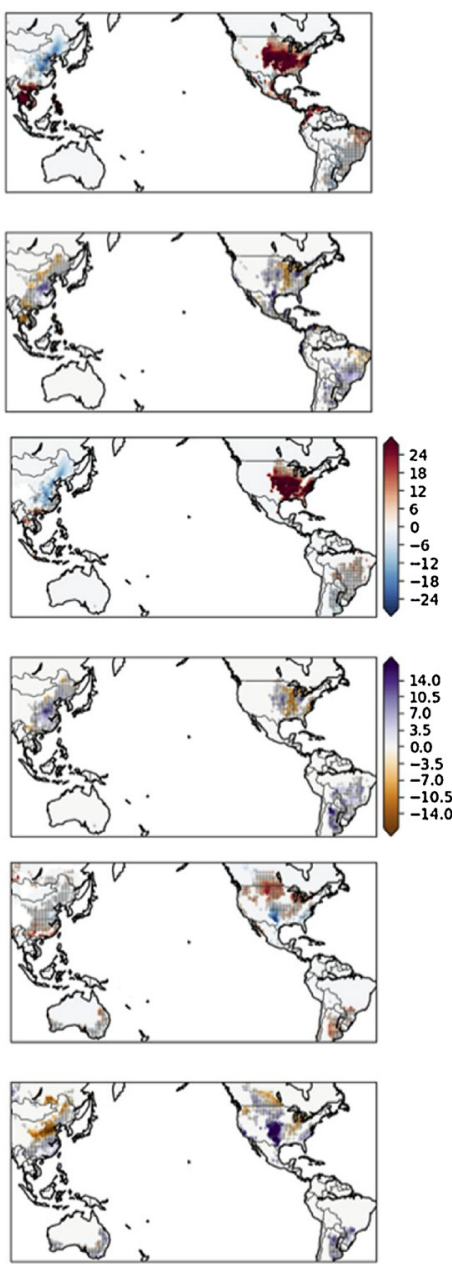

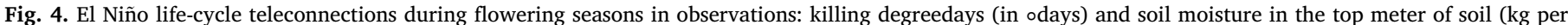
square meter). Croppedareas without at least $2 / 3$ of ENSO events agreeing on the sign of the teleconnection are shaded.

induced circulation anomalies persist through the wheat flowering seasons in China and the US. These modeling results confirm the dominance of the tropical Pacific Ocean forcing of the trans-Pacific teleconnections.

\subsection{Life cycles of ENSO teleconnections during local flowering seasons}

\subsubsection{Maize and soybean growing season teleconnections}

El Niños and La Niñas impose a fairly robust structure of teleconnections across hemispheres during maize and soybean flowering seasons such that northern China, southern Mexico and northeast Brazil have anomalies of one sign while the United States and Argentina experience anomalies of the opposite sign. Figs. 4 and 5 show how the teleconnections influence KDD and soil moisture. During an El Niño (ENO and LN-1) year the maize/soybean flowering seasons in northern China, northeast Brazil and southern Mexico are hot and dry, while the flowering seasons in Argentina are temperate and wet (see Figs. 4 and 5). Conditions in the US are mixed. During LNO these anomalies reverse: high maximum temperatures over much of the Americas and dry soils in the United States lead to poor growing conditions, while in northern China and southern Mexico moderate temperatures and high soil moisture is favorable for crop development. Although the LNO maximum temperature and soil moisture anomalies in the United States are more prominent than may have been inferred from the mid-season atmospheric teleconnections, they are likely stable as evidenced by the relation between ENSO and maize yields found in long data records (Handler, 1984; Phillips et al., 1999).

Teleconnections during second year La Niñas $(\mathrm{LN}+1)$ bear little resemblance to LNO teleconnections. This is unsurprising for the northern hemisphere, where the mid-season geopotential height anomalies are different between LNO and LN + 1 (see Fig. 3) but is less intuitive for maize and soybeans in southeast South America, where the late-season atmospheric anomalies in $\mathrm{LN}+1$ are similar to, although weaker than, those in LNO.

The AMIP multi-model mean supports the observational analysis in that maize flowering seasons in northern China, southern Mexico and northeast Brazil tend to vary together and in the opposite sense of the United States and southeast South America (Figs. 6 and 7). During El Niño years (EN0, LN-1) northern China, southern Mexico and northeast Brazil are all hot and dry, while the United States and southeast South America are cool and wet. During first and second year La Niñas (LNO, $\mathrm{LN}+1$ ) this pattern of moisture and temperature anomalies reverse with the exception of maximum temperature anomalies in China and Brazil during LNO (Fig. 7. The anomalies during LN-1/ENO events and their reversal in LNO is clear, and implies robust teleconnections. The results from the AMIP experiments agree well with the observational evidence during ENO and LNO (compare Figs. 6 and 7 with Figs. 4 and 5). The AMIP teleconnections during $\mathrm{LN}+1$, however, are generally not present in the observational record and so should be interpreted with caution. Disagreement could be caused by the observational 

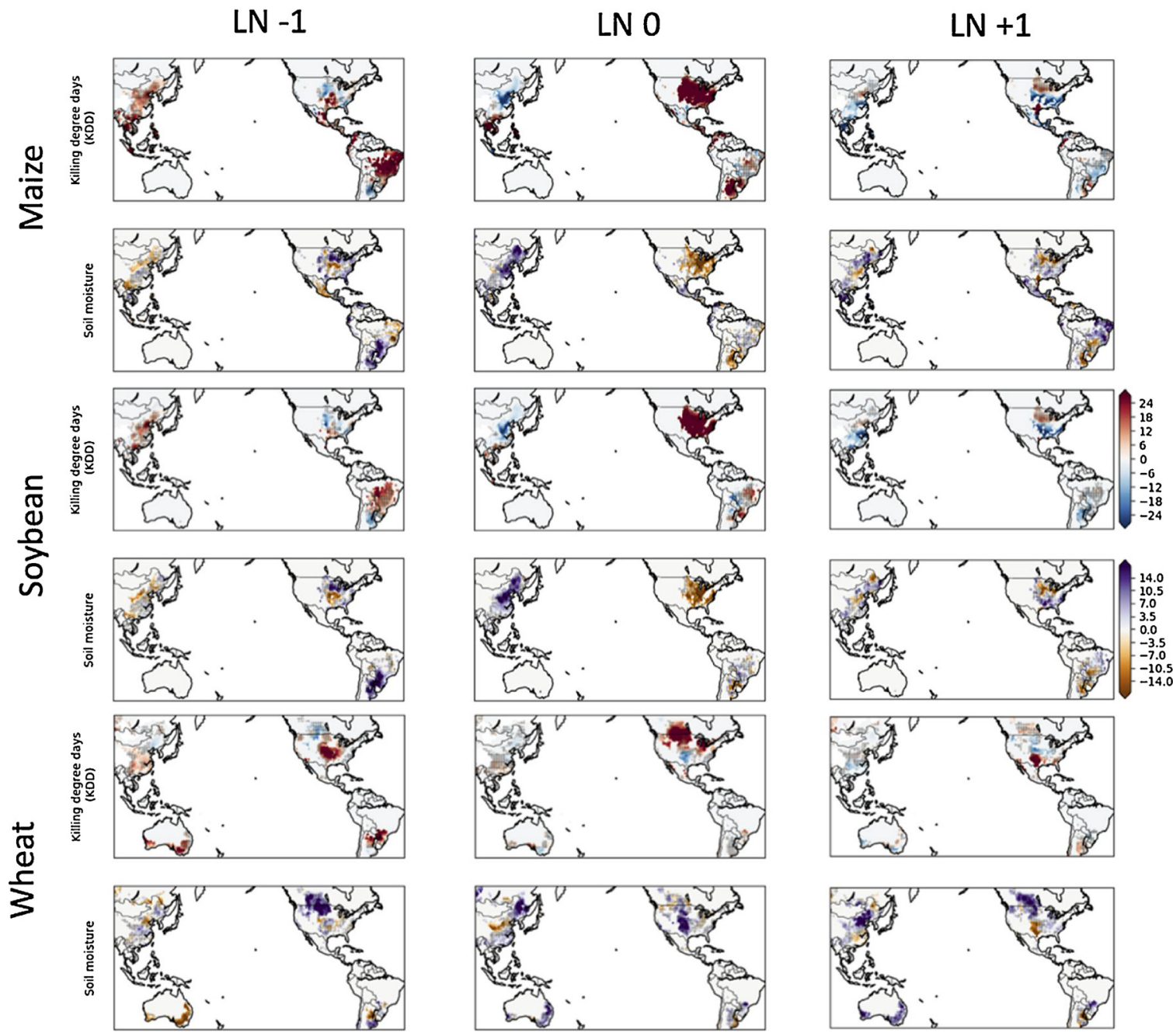

Fig. 5. La Niña life-cycle teleconnections during flowering seasons in observations: killing degreedays (in odays) and soil moisture in the top meter of soil (kg per square meter). Croppedareas without at least $2 / 3$ of ENSO events agreeing on the sign of the teleconnection are shaded.

results for $\mathrm{LN}+1$ not being only ocean-forced, or by model error in simulating genuine teleconnections during $\mathrm{LN}+1$.

\subsubsection{Wheat growing season teleconnections}

The structure of risks imposed by ENSO during wheat flowering seasons is more complicated than that for maize/soybeans both because the dynamics are more complex (e.g. lagged teleconnections become important) and because the response of yields to increased precipitation is less straightforward (e.g. disease is a potential problem in South America; Cunha et al. (2001)). During EN0/LN-1 years, maximum temperatures are above average in southern China, the United States, southern Brazil and Australia (see Figs. 4 and 5). These temperature anomalies are accompanied by dry anomalies in Australia, but wet anomalies in parts of Argentina. During LNO damaging heat is only present in the northern Great Plains of Canada and the United States.

Because the northern hemisphere wheat flowering season immediately follows peak SST anomalies during ENSO events (see Fig. 1), lagged teleconnections play a significant role in determining moisture anomalies in China and the United States. During boreal spring in the United States, Mauget and Upchurch (1999) and Anderson et al. (2016) demonstrate that soil moisture anomalies in the southern Great Plains during the wheat flowering season are significantly influenced by ENSO-induced precipitation anomalies in the previous season. Combined with same-season teleconnections, this forces wet soil moisture anomalies in the year following an El Niño (EN + 1 in Fig. 4, LNO in Fig. 5). Lagged teleconnections, however, can also be maintained by
SST anomalies. In agreement with Wang et al., (2000), we find that during boreal winter of an El Niño year an anticyclonic circulation forms off the east coast of China in the lower troposphere and persists into the spring of the following year due to air-sea interactions (Fig. 2), which maintains poleward flow and increases precipitation over southeast China (LNO in Fig. 5).

The AMIP multi-model mean clearly demonstrates the zonal asymmetry of the teleconnections in the southern hemisphere present in observations: hot and dry conditions in Australia coincide with wet, cool conditions in Argentina (Figs. 6 and 7). Furthermore, Australia is wet during both LNO and LN +1 in both observations and the AMIP models, while Argentina is dry and hot.

In the northern hemisphere the AMIP models agree with observations in some places but disagree in others. In the observations, the Great Plains of the United States in the year following an El Niño (EN + 1, LN0) are cool, while the year following a La Niña $(L N+1)$ is dry and hot. The extreme heat in the northern Great Plains during LNO, however, is absent in the AMIP runs. In China during an El Niño (ENO) the AMIP models indicate uniformly hot conditions, while the observations are mixed (Fig. 7). The AMIP models also disagree with observations during $\mathrm{LN}+1$.

\section{Discussion}

We can now return to the first of the questions we asked in our introduction: how are ENSO teleconnections during climate-sensitive 

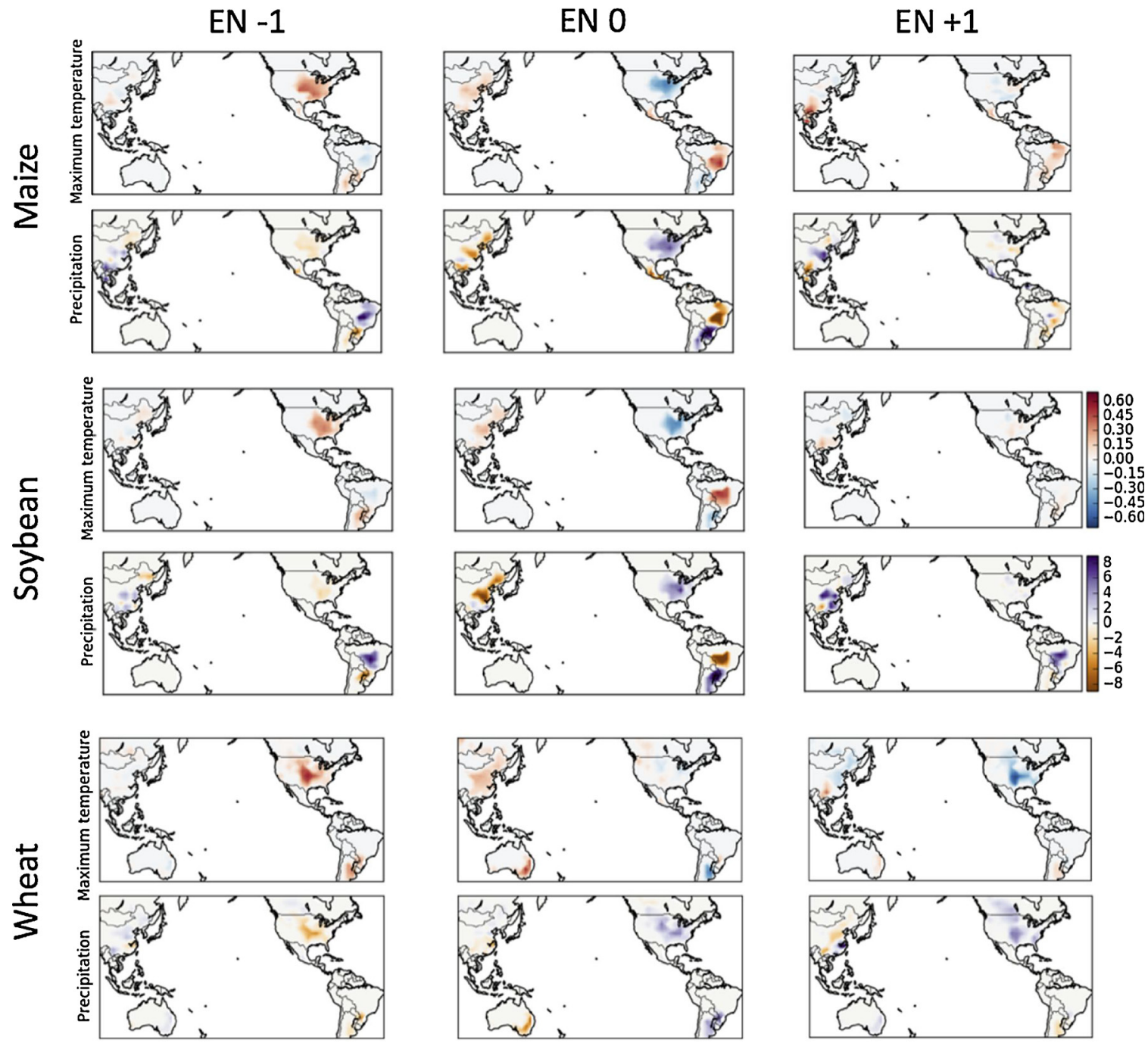

Fig. 6. AMIP multi-model mean of teleconnections during El Niño life-cycles during floweringseasons: maximum temperature (in oC; top panel), seasonal precipitation (in $\mathrm{mm}$; second panel.

portions of growing seasons in the Americas, China and Australia related to one another? Trans-Pacific ENSO teleconnections evolve over multiple years at a basin-wide spatial scale and affect growing seasons on continents in all four corners of the Pacific (Figs. 2 and 3). The majority of these teleconnections are part of a single circulation anomaly (see Appendix Fig. A1), which develops in late summer and persists through to the early spring. This means that most ENSO-induced yield anomalies are closely and coherently related to one-another. These trans-Pacific teleconnections are illustrated schematically in Figs. 8 and 9 for El Niño and La Niña life cycles, respectively.

During the late summer and early fall of a developing El Niño event, there are teleconnections to growing seasons on all four continents around the Pacific Basin (the Americas, Asia and Australia; Fig. 8). As the El Niño event intensifies in boreal winter, it affects flowering seasons in southeast South America and forces SST anomalies in the IndoWest Pacific. In the spring and summer following an El Niño event, these SST anomalies in the Indo-West Pacific influence the climate of southern China and Australia while teleconnections from the tropical Pacific affect flowering seasons in northern China and the United States.

La Niñas often develop immediately after El Niños (although this is not always the case) and have teleconnections that are roughly opposite to those of El Niño. The life cycle of La Niña teleconnections, therefore, begins in LN-1 with the teleconnections of El Niño, which then reverse sign during La Niña (LNO). Negative SST anomalies tend to persist for two years, such that some La Niña teleconnections - particularly in the southern hemisphere - persist for two years as well (see Fig. 9).

As most trans-Pacific ENSO teleconnections are coherent, we turn to our next question: within a single growing year, are ENSO teleconnections in major producing regions generally compounding or offsetting? For maize and soybeans, we find that growing conditions are generally of the same sign in major producing regions of the Americas (i.e. southeast South America and the US) but are opposite to those in northern China (Figs. 4-7). For example, El Niño events tend to create good maize and soybean growing conditions in the US and southeast South America, but poor maize growing conditions in northern China, southern Mexico and northeast Brazil (see Figs. 4 and 6). The opposite is true during La Niña (Figs. 5 and 7). ENSO teleconnections that affect wheat growing seasons are more complex, including same-season teleconnections to Australia and Argentina, and lagged teleconnections to China and the United States. ENSO teleconnections to wheat growing conditions in Australia and Argentina tend to have opposite signs (although sometimes this may produce same-sign yield anomalies due to high moisture and frequent disease problems in Argentina). Northern hemisphere teleconnections to southern China are opposite to those in the US during the spring following an ENSO event. Trans-Pacific ENSO teleconnections, therefore, analogous to the climate anomalies themselves, are often (but not always) offsetting in terms of yield impact between the Americas and China or Australia. 

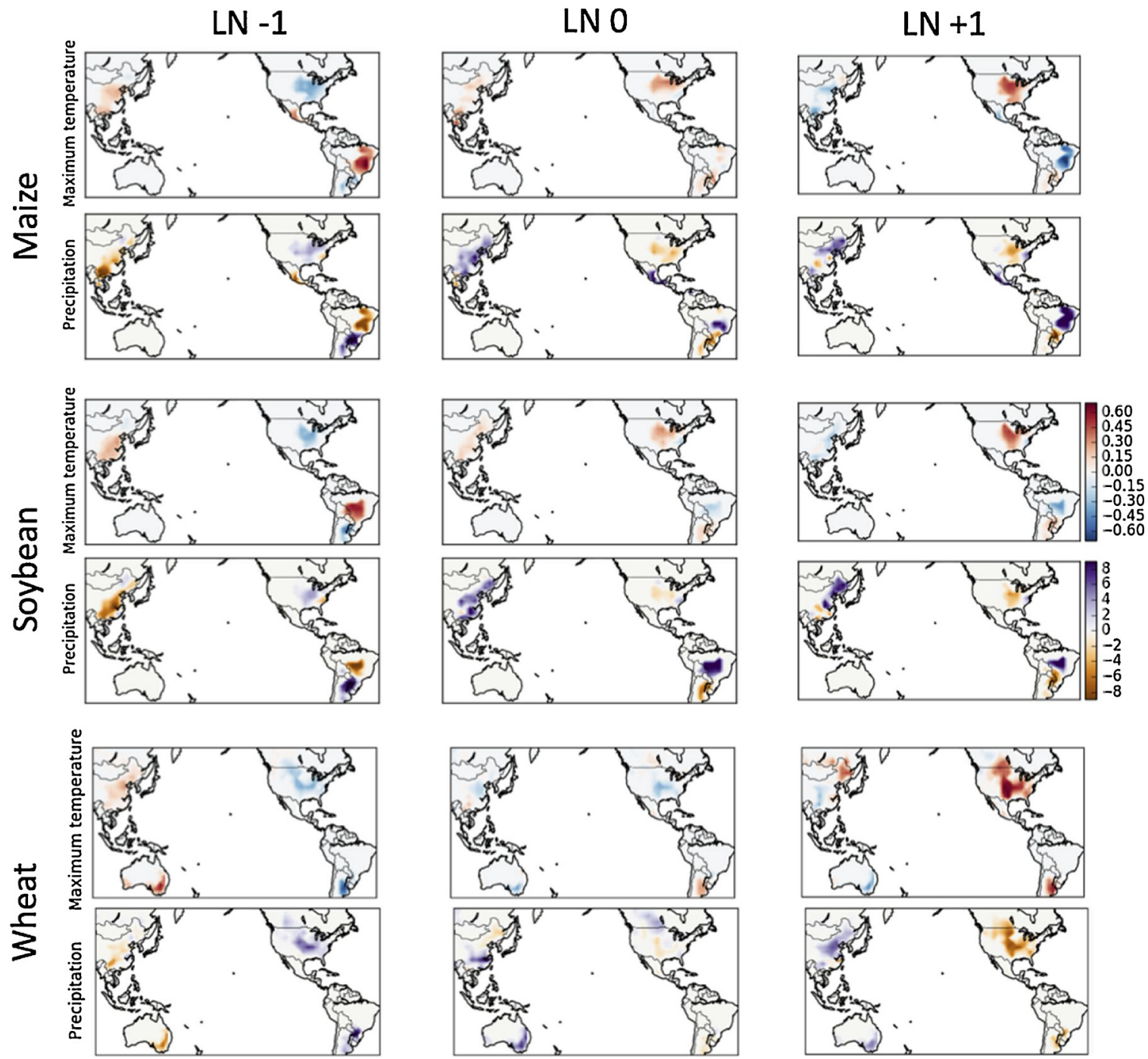

Fig. 7. AMIP multi-model mean of teleconnections during La Niña life-cycles during floweringseasons: maximum temperature (in oC; top panel), seasonal precipitation (in $\mathrm{mm}$; second panel).

\section{Conclusions}

The characteristic multi-year, basin-wide evolution of trans-Pacific ENSO teleconnections poses a series of interrelated risks to our food production system. We find that most ENSO teleconnections relevant for crop flowering seasons are the result of a single tropical-extratropical circulation anomaly pattern that develops in late boreal summer and persists through the early spring. This circulation anomaly affects the climate on continents in all four corners of the Pacific basin. During the late summer and early fall of a developing ENSO event, the tropical Pacific forces an atmospheric response in the northern midlatitudes that spans the Pacific from northern China to North America and in the southern midlatitudes from Australia to southeast South America. This teleconnection directly links the soybean and maize growing seasons of the US, Mexico and China. It also connects the wheat growing seasons of Argentina, southern Brazil and Australia. The ENSO event peaks in boreal winter, when the atmospheric circulation anomalies intensify and affect maize and soybeans in southeast South America. As the event decays, the ENSO-induced circulation anomalies persist through the wheat flowering seasons in China and the US.
From the perspective of global food security, it is fortunate that during the maize and soybean growing season ENSO anomalies in major food-producing regions in the Americas are often balanced by opposite-signed anomalies in northern China or Australia. Maize and soybean growing conditions in the US and Argentina, for example, may be balanced by those in northern China and northeastern Brazil. And although wheat growing conditions are less straightforward, dry (wet) conditions during flowering months in Australia seem to be balanced by wet (dry) conditions in southeast South America.

The timing and spatial structure of ENSO teleconnections can be leveraged to improve monitoring of food security and management of food stocks. For example, because La Niñas develop following El Niños, the good harvests of soybeans associated with El Niño years in the Americas (Anderson et al., 2017) could be used to mitigate poorer harvests that often accompany subsequent La Niña years. Our analysis represents a first small step towards improving food security by identifying structural risks imposed on agriculture by trans-Pacific ENSO teleconnections. Future work will relate the climate anomalies studied here to yield anomalies to determine life cycles of trans-Pacific ENSOinduced food production variability. 
EN -1
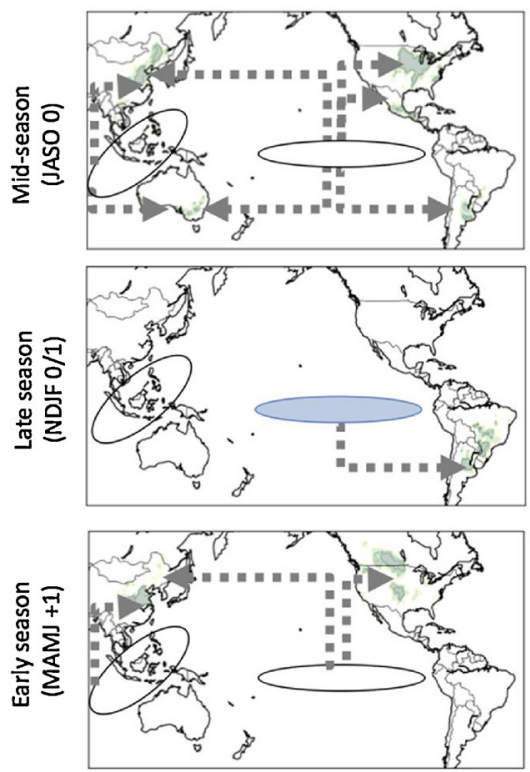

Flowering in major producing region for wheat, maize or soy
EN 0
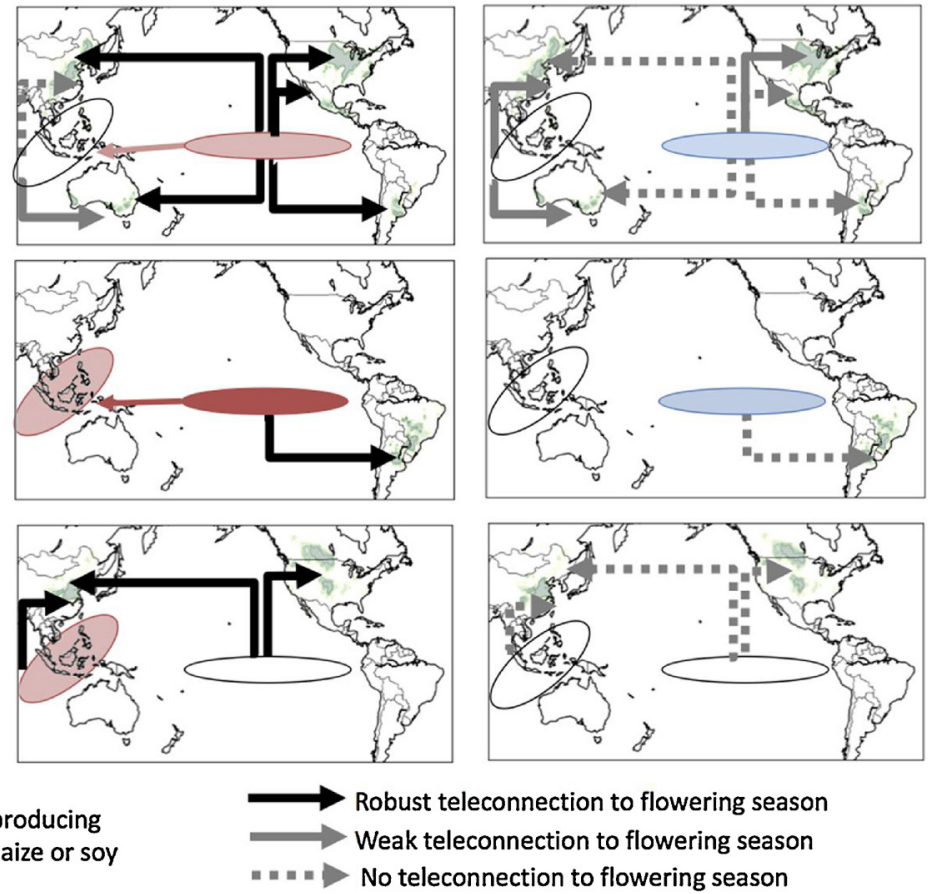

EN 1
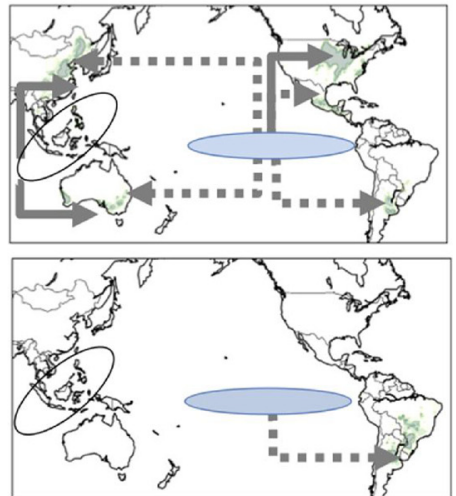

$= \pm=$ No teleconnection to flowering season

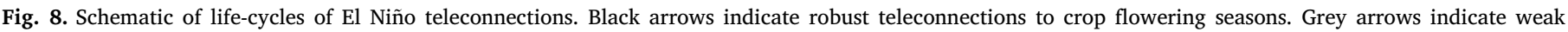

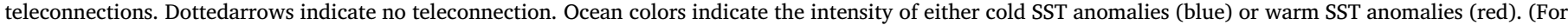
interpretation of the references to colour in this figure legend, the reader is referred to the web version of this article).
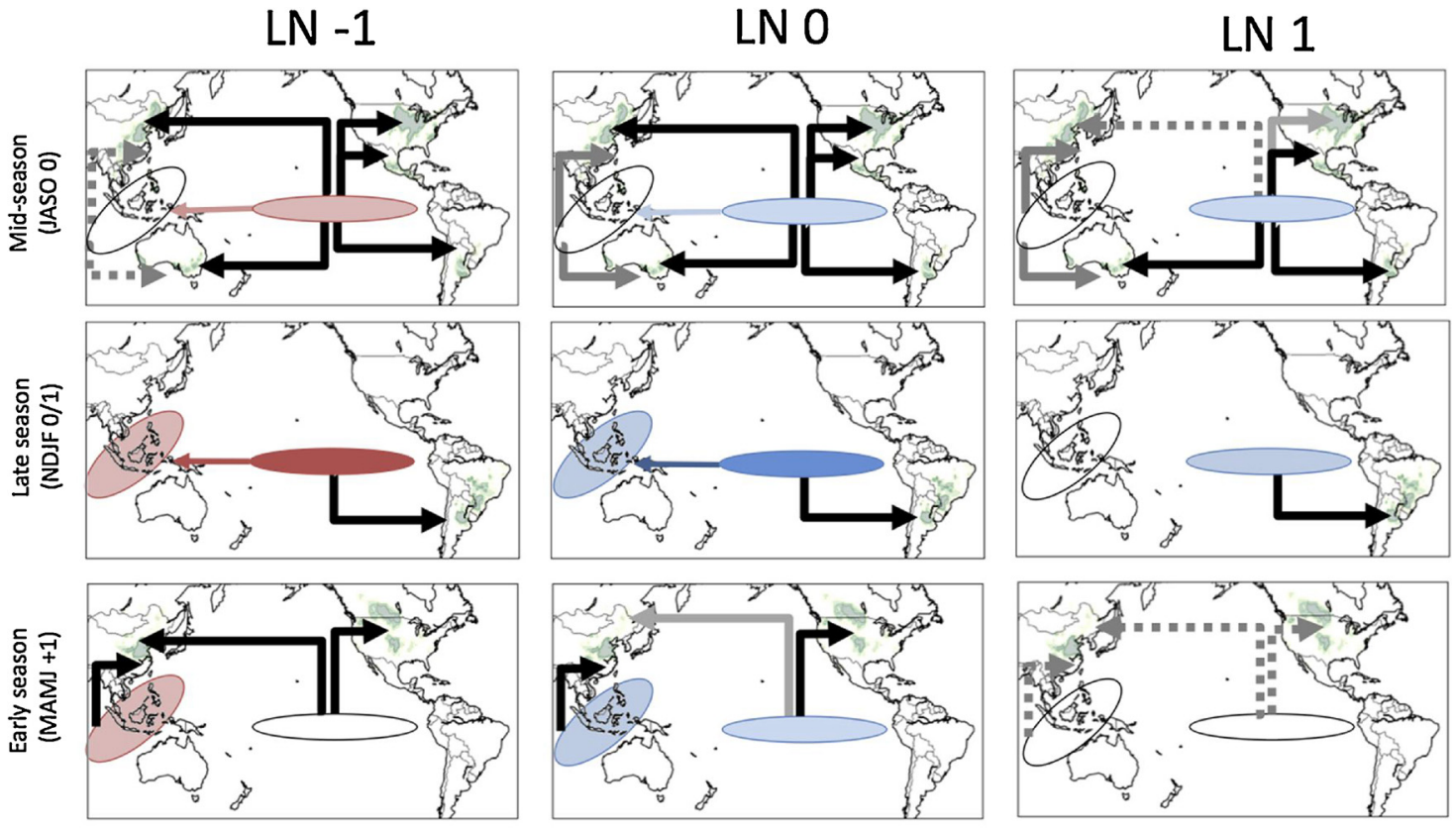

Flowering in major producing region for wheat, maize or soy
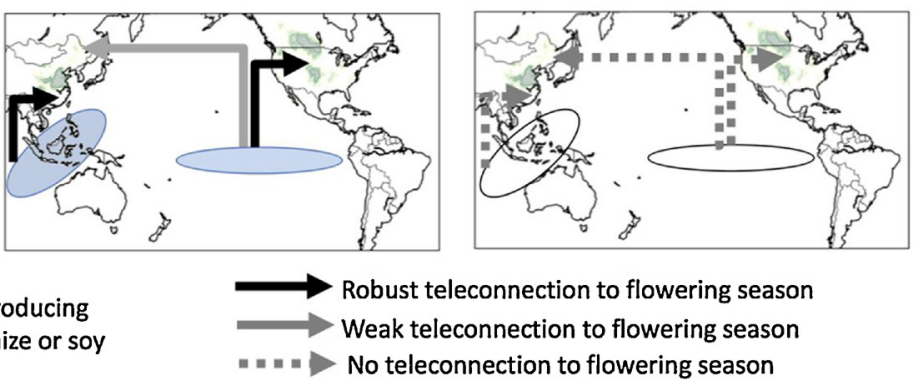

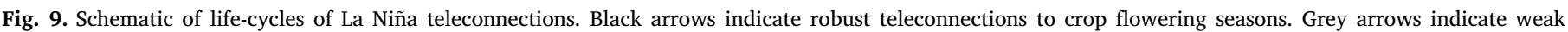
teleconnections. Dottedarrows indicate no teleconnection. Ocean colors indicate the intensity of either cold SST anomalies (blue) or warm SST anomalies (red).

\section{Acknowledgments}

We would like to thank Haibo Liu and Naomi Henderson for help accessing AMIP model simulations. We are also grateful to Deepti Singh for helpful discussions during the development of our analyses, and to two anonymous reviewers for their constructive comments. This material is based upon work supported by the National Science Foundation Graduate Research Fellowship under Grant No. DGE-11-44155. RS acknowledges support from NSF award AGS-1401400. 


\section{Appendix A}

\section{Troical Pacific atmospheric teleconnections}

To isolate teleconnections forced by the tropical Pacific SSTs, we make use of a set of AMIP-style runs form 1948-2007 that force an atmospheric general circulation model (CCM3) with observed SST anomalies in the tropical Pacific and climatological SSTs elsewhere (Seager et al., 2005). This set of analyses allows us to explicitly identify the atmospheric teleconnections associated with forcing only in the tropical Pacific. Appendix Fig. A1 shows the seasonal evolution of atmospheric teleconnections for $200 \mathrm{hPa}$ (El Niño - La Niña). Spatially, the tropical Pacific-only teleconnections span the Pacific Basin and connect all four hemispheres. Temporally, the teleconnections develop in JASO, peak in NDJF and persist into MAMJ.

Observations
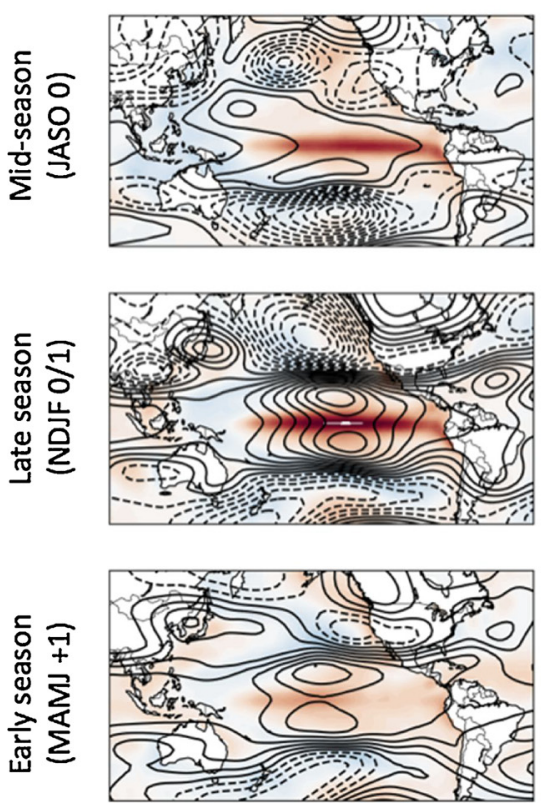

Pacific ocean forced
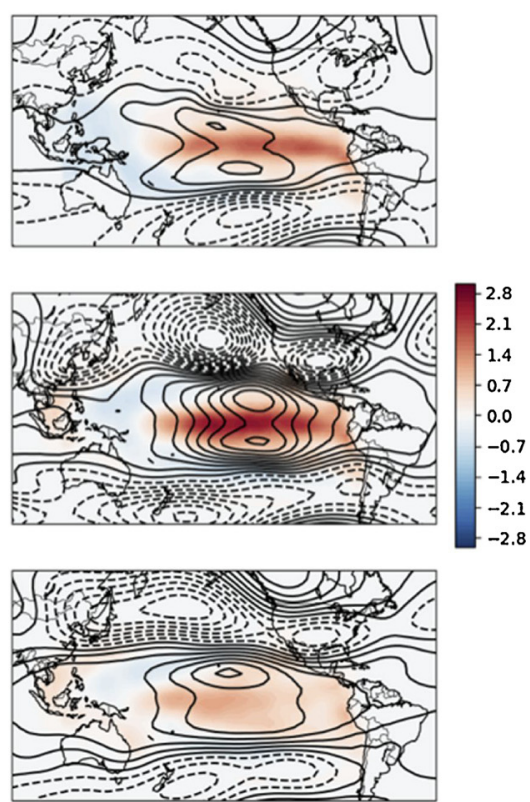

Fig. A1. El Niño - La Niña 200 hPa geopotential height anomalies in observations (first column) and those forced by the Pacific ocean (second column). SST anomalies shown in $\circ \mathrm{C}$ (colors). (For interpretation of the references to colour in this figure legend, the reader is referred to the web version of this article).

\section{References}

Alexander, M.A., Blade, I., Newman, M., Lanzante, J.R., Lau, N.-C., Scott, J.D., 2002. The atmospheric bridge: the influence of enso teleconnections on air-sea interaction over the global oceans. J. Clim. 15 (16), 2205-2231.

Anderson, W., Seager, R., Baethgen, W., Cane, M., 2016. Life cycles of agriculturallyrelevant ENSO teleconnections in North and South America. Int. J. Climatol.

Anderson, W., Seager, R., Baethgen, W., Cane, M., 2017. Crop production variability in North and South America forced by life-cycles of the El Niño Southern Oscillation. Agric. For. Meteorol. 239, 151-165.

Annamalai, H., Liu, P., Xie, S.-P., 2005. Southwest Indian Ocean SST variability: its local effect and remote influence on Asian monsoons. J. Clim. 18 (20), 4150-4167.

Barnabás, B., Jäger, K., Fehér, A., 2008. The effect of drought and heat stress on reproductive processes in cereals. Plant Cell Environ. 31 (1), 11-38.

Bjerknes, J., 1969. Atmospheric teleconnections from the equatorial Pacific. Mon. Weather Rev. 97 (3), 163-172. https://doi.org/10.1175/1520-0493(1969) 097<0163:ATFTEP〉2.3.CO;2

Cazes-Boezio, G., Robertson, A.W., Mechoso, C.R., 2003. Seasonal dependence of ENSO teleconnections over South America and relationships with precipitation in Uruguay. J. Clim. 16 (8), 1159-1176.

Chiew, F.H., Piechota, T.C., Dracup, J.A., McMahon, T.A., 1998. El Niño/Southern Oscillation and Australian rainfall, streamflow and drought: Links and potential for forecasting. J. Hydrol. 204 (1-4), 138-149.

Cunha, G., Dalmago, G., Estefanel, V., 2001. ElNiño Southern Oscillation Influences on Wheat Crop in Brazil. Wheat in a Global Environment. Springer, pp. 445-450.

d'Amour, C.B., Wenz, L., Kalkuhl, M., Steckel, J.C., Creutzig, F., 2016. Teleconnected food supply shocks. Environ. Res. Lett. 11 (3) 035007.

DiNezio, P.N., Deser, C., 2014. Nonlinear controls on the persistence of la niña. J. Clim. 27 (19), 7335-7355.

Gill, A., 1980. Some simple solutions for heat-induced tropical circulation. Q. J. R. Meteorol. Soc. 106 (449), 447-462.

Grimm, A.M., 2003. The El Niño impact on the summer monsoon in Brazil: regional processes versus remote influences. J. Clim. 16 (2), 263-280.

Grimm, A.M., Ferraz, S.E., Gomes, J., 1998. Precipitation anomalies in southern Brazil associated with El Niño and La Niña events. J. Clim. 11 (11), 2863-2880.
Grimm, A.M., Barros, V.R., Doyle, M.E., 2000. Climate variability in southern South Amer- ica associated with El Niño and La Niña events. J. Clim. 13 (1), 35-58.

Handler, P., 1984. Corn yields in the United States and sea surface temperature anomalies in the equatorial Pacific Ocean during the period 1868-1982. Agric. For. Meteorol. 31 (1), 25-32.

Iizumi, T., Luo, J.-J., Challinor, A.J., Sakurai, G., Yokozawa, M., Sakuma, H., Brown, M.E., Yamagata, T., 2014. Impacts of El Niño Southern Oscillation on the global yields of major crops. Nat. Commun. 5 (May), 3712. https://doi.org/10.1038/ncomms4712. http://www.ncbi.nlm.nih.gov/pubmed/24827075.

Kalnay, E., et al., 1996. The NCEP/NCAR 40-year reanalysis project. Bull. Am. Meteorol. Soc. 77 (3), 437-471.

Klein, S.A., Soden, B.J., Lau, N.-C., 1999. Remote sea surface temperature variations during ENSO: evidence for a tropical atmospheric bridge. J. Clim. 12 (4), 917-932.

Marchand, P., et al., 2016. Reserves and trade jointly determine exposure to food supply shocks. Environ. Res. Lett. 11 (9) 095009.

Mason, S.J., Goddard, L., 2001. Probabilistic precipitation anomalies associated with ENSO. Bull. Am. Meteorol. Soc. 82 (4), 619-638.

Matsuno, T., 1966. Quasi-geostrophic motions in the equatorial area. J. Meteorol. Soc. Jpn. Ser. II 44 (1), 25-43.

Mauget, S.A., Upchurch, D.R., 1999. El Niño and La Niña related climate and agricultural impacts over the Great Plains and Midwest. J. Prod. Agric. 12 (2), 203-215.

Monfreda, C., Ramankutty, N., Foley, J.A., 2008. Farming the planet: 2. Geographic distribution of crop areas, yields, physiological types, and net primary production in the year 2000. Glob. Biogeochem. Cycles 22 (1).

Okumura, Y.M., Deser, C., 2010. Asymmetry in the duration of el niño and la niña. J. Clim. 23 (21), 5826-5843.

Phillips, J., Rajagopalan, B., Cane, M., Rosenzweig, C., 1999. The role of ENSO in determining climate and maize yield variability in the U.S. cornbelt. Int. J. Climatol. 19, 877-888. https://doi.org/10.1002/(SICI)1097-0088(19990630)19:8877::AIDJOC406>3.0.CO;2-Q.

Puma, M.J., Bose, S., Chon, S.Y., Cook, B.I., 2015. Assessing the evolving fragility of the global food system. Environ. Res. Lett. 10 (2) 024007.

Rasmusson, E.M., Carpenter, T.H., 1982. Variations in tropical sea surface temperature and surface wind fields associated with the Southern Oscillation/El Niño. Mon. Weather. Rev. 110 (5), 354-384.

Rodell, M., Kato Beaudoing, H., 2015. GLDAS Noah Land Surface Model L4 Monthly 1.0 
$\times$ 1.0 Degree Version 2.0,version 020. Tech. rep., NASA/GSFC/HSL (12.01.2013). Goddard Earth Sciences Data and Information Services Center (GES DISC), Greenbelt, Maryland, USA. https://doi.org/10.5067/QN80TO7ZHFJZ.

Rohde, R., Muller, R.A., Jacobsen, R., Muller, E., Perlmutter, S., Rosenfeld, A., Wurtele, J., Groom, D., Wickham, C., 2013a. A new estimate of the average Earth surface land temperature spanning 1753 to 2011. Geoinformatics Geostat. Overview 1 (1 of 7), 2.

Rohde, R., Muller, R., Jacobsen, R., Perlmutter, S., Rosenfeld, A., Wurtele, J., Curry, J., Wickhams, C., Mosher, S., 2013b. Berkeley earth temperature averaging process. Geoinformatics Geostat: Overview 1 (2 of 13), 20-100.

Sacks, W.J., Deryng, D., Foley, J.A., Ramankutty, N., 2010. Crop planting dates: an analysis of global patterns. Glob. Ecol. Biogeogr. 19 (5), 607-620.

Schlenker, W., Roberts, M.J., 2009. Nonlinear temperature effects indicate severe damages to us crop yields under climate change. Proc. Natl. Acad. Sci. 106 (37), 15 594-15 598.

Seager, R., Kushnir, Y., Herweijer, C., Naik, N., Velez, J., 2005. Modeling of tropical forcing of persistent droughts and pluvials over western North America: 1856-2000. J. Clim. 18 (19), 4065-4088.

Siebers, M.H., Slattery, R.A., Yendrek, C.R., Locke, A.M., Drag, D., Ainsworth, E.A., Bernacchi, C.J., Ort, D.R., 2017. Simulated heat waves during maize reproductive stages alter reproductive growth but have no lasting effect when applied during vegetative stages. Agrc. Ecosyst. Environ. 240, 162-170.

Smith, T.M., Reynolds, R.W., Peterson, T.C., Lawrimore, J., 2008. Improvements to NOAA's historical merged land-ocean surface temperature analysis (1880-2006). J. Clim. 21 (10), 2283-2296.

Tai, A.P., Martin, M.V., Heald, C.L., 2014. Threat to future global food security from climate change and ozone air pollution. Nat. Clim. Change 4 (9), 817.

Taschetto, A.S., Sen Gupta, A., Hendon, H.H., Ummenhofer, C.C., England, M.H., 2011 The contribution of Indian Ocean sea surface temperature anomalies on Australian summer rainfall during El Niño events. J. Clim. 24 (14), 3734-3747.

Taylor, K.E., Stouffer, R.J., Meehl, G.A., 2012. An overview of CMIP5 and the experiment design. Bull. Am. Meteorol. Soc. 93 (4), 485-498.

Trenberth, K.E., Branstator, G.W., Karoly, D., Kumar, A., Lau, N.-C., Ropelewski, C., 1998. Progress during TOGA in understanding and modeling global teleconnections associated with tropical sea surface temperatures. J. Geophys. Res. Oceans 103 (C7), 14 291-14 324.

Wang, C., Picaut, J., 2004. Understanding ENSO physics - a review. Geophys. Monogr. Ser. 147, 21-48. https://doi.org/10.1029/GM147.

Wang, B., Wu, R., Fu, X., 2000. Pacific-East Asian teleconnection: how does ENSO affect East Asian climate? J. Clim. 13 (9), 1517-1536.

Wang, B., Wu, R., Lau, K., 2001a. Interannual variability of the Asian summer monsoon: contrasts between the Indian and the western North Pacific-East Asian monsoons. J. Clim. 14 (20), 4073-4090.

Wang, Y., Wang, B., Oh, J.-H., 2001b. Impact of the preceding El Niño on the East Asian summer atmosphere circulation. J. Meteorol. Soc. Jpn. 79 (1B), 575-588.

Weng, H., Ashok, K., Behera, S.K., Rao, S.A., Yamagata, T., 2007. Impacts of recent El Niño Modoki on dry/wet conditions in the Pacific rim during boreal summer. Clim. Dyn. 29 (2-3), 113-129.

Wu, B., Li, T., Zhou, T., 2010. Relative contributions of the Indian Ocean and local SST anomalies to the maintenance of the western North Pacific anomalous anticyclone during the El Niño decaying summer. J. Clim. 23 (11), 2974-2986.

Xie, S.-P., Hu, K., Hafner, J., Tokinaga, H., Du, Y., Huang, G., Sampe, T., 2009. Indian Ocean capacitor effect on Indo-western Pacific climate during the summer following El Niño. J. Clim. 22 (3), 730-747.

Yang, J., Liu, Q., Xie, S.-P., Liu, Z., Wu, L., 2007. Impact of the Indian Ocean SST basin mode on the Asian summer monsoon. Geophys. Res. Lett. 34 (2).

Yang, J., Liu, Q., Liu, Z., 2010. Linking observations of the Asian monsoon to the Indian Ocean SST: possible roles of Indian Ocean basin mode and dipole mode. J. Clim. 23 (21), 5889-5902

Zhou, J., Lau, K.-M., 2001. Principal modes of interannual and decadal variability of summer rainfall over South America. Int. J. Climatol. 21 (13), 1623-1644. 